Document downloaded from:

http://hdl.handle.net/10251/98699

This paper must be cited as:

Climente Alarcon, V.; J. Antonino-Daviu; Vedreño Santos, FJ.; Rubén Puche-Panadero (2013). Vibration Transient Detection of Broken Rotor Bars by PSH Sidebands. IEEE Transactions on Industry Applications. 49(6):2576-2582. doi:10.1109/TIA.2013.2265872

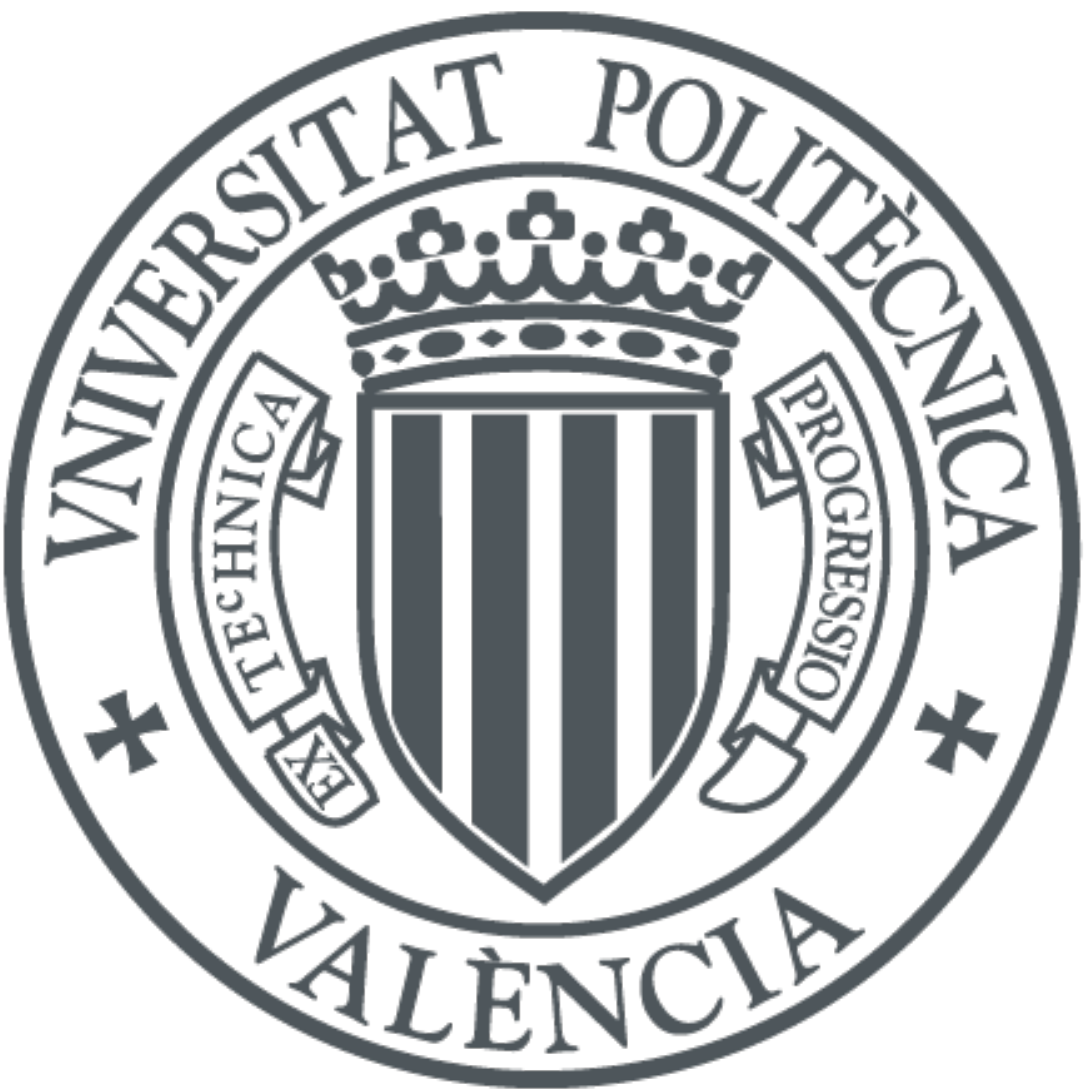

The final publication is available at

http://doi.org/10.1109/TIA.2013.2265872

Copyright Institute of Electrical and Electronics Engineers

Additional Information 


\title{
Vibration Transient Detection of Broken Rotor Bars by PSH Sidebands
}

\author{
Vicente Climente-Alarcon, Member, IEEE, José Antonino-Daviu, Senior Member, IEEE, Francisco \\ Vedreño-Santos and Rubén Puche-Panadero, Member, IEEE.
}

\begin{abstract}
In recent years, the study of transients of induction motors for diagnosis purposes has gained strength in order to overcome some inherent problems of the classical diagnosis of such machines, which uses Fourier analysis of steady-state quantities. Novel time-frequency techniques have been applied to these transient quantities, in order to detect the characteristic evolutions of fault-related harmonic components. The detection of these patterns, which are usually specific for each type of fault, enables reliable diagnostic of the corresponding failures. In this context, most of the works hitherto developed have been based on analysis of currents. However, in some applications vibration measurements are also available. The goal of this work is to validate the applicability of this transient-based diagnosis framework to vibration measurements. A specific time-frequency decomposition tool, the Zhao-Atlas-Marks distribution, is proposed. Experimental results prove the ability of the approach to complement the information obtained from the current analysis. This may be very useful in applications in which the diagnosis via currents is uncertain or in which vibration signals can be easily measured.
\end{abstract}

Index Terms - Fault diagnosis, frequency domain analysis, induction motors, transient analysis, vibrations

\section{INTRODUCTION}

$\mathrm{T}$ he feeding and operation of induction motors make their diagnosis through mechanical vibrations especially suitable. Since flux density generates radial magnetic forces between the stator and the rotor surfaces, and the latter, as it rotates, also causes similar forces, any incipient failure can be translated into an increase of the mechanical vibration levels.

Alterations in the air-gap length, for instance, change the amplitude of the flux density and, hence, vibration levels are modified. If this process is caused by dynamic eccentricity, the minimum air-gap moves together with the rotor, generating an unbalanced magnetic pull, which appears as a component in the vibration spectrum at the same frequency $f_{r}$ the rotor spins [1]. Since all machines have a certain level of

This work was supported by the Spanish Ministerio de Ciencia e Innovación (MICINN) in the framework of the VI Plan Nacional de Investigación Científica, Desarrollo e Innovación Tecnológica 2008-2011. (Programa Nacional de Proyectos de Investigación Fundamental, project reference DPI2011-23740).

The authors are with the Instituto de Ingeniería Energética, Universitat Politècnica de València, Camino de Vera s/n, 46022, Valencia, SPAIN, (phone: 0034-963877592, fax: 0034-963877599, e-mails: viclial@ieee.org, joanda@die.upv.es, fravedsa@etsii.upv.es,rupucpa@die.upv.es). dynamic eccentricity, due to manufacturing tolerances, this component as well as its harmonics at frequencies $n \cdot f_{r}$, being $n$ and integer, are customary in the vibration spectrum.

In addition, stator and often rotor surfaces are not smooth, but openings are built in order to facilitate the arrangement of the primary and secondary windings. These slotted faces cause flux density fluctuations in the air-gap, being prevalent in a loaded machine the ones produced by the currents circulating through the rotor bars [2], known as Principal Slot Harmonics or PSH. Since their variation is proportional to the number of rotor bars, their frequencies usually fall above $500 \mathrm{~Hz}$. This frequency range is not often studied in vibration diagnosis of induction motors, but rather in noise level prediction during motor design [1].

Finally, the vibration spectrum of an induction motor also features components at twice the line frequency and its harmonics, produced by the rotation of the magnetic flux wave. In this case, the amplitude of such components is constant with load [1].

On these typical components, faults act in two ways. Dynamic eccentricity and other mechanical related faults, such as misaligned coupling, tend to increase the amplitude of the rotating frequency component and/or its harmonics [1]. Static eccentricity will affect the twice supply line component, whilst stator and broken bar faults will also affect the rotating frequency harmonics [3].

In addition, on some kind of faults new components appear. The negative sequence component of the magnetic flux wave caused by a rotor broken bar produces a torque ripple at frequency $2 s f$, which modulates the main harmonics existing in the vibration spectrum. Such modulation is a clear sign of the presence of this fault [4].

Although the sources of vibration act in such concise way, the final response is complicated since other factors, as the mode shape of the vibrations, defined by spatial order of these waves, or mechanical resonances, contribute to the variation of their amplitudes [5].

Therefore, for rotating machines, vibrations are usually measured in places close to each bearing, in the three directions: horizontal, vertical (for radial vibrations) and axial. This information is useful since the vibration of the rotating element is transmitted to the bearings. The effect is more acute in ball bearings rather than in sleeve bearings. Other vibration measurements could be taken in any other 
point of interest for solving a specific problem [1].

The study of vibrations for the diagnosis of induction machines has been widespread since the seminal work from Cameron et Al. [2] for this method is non-invasive, and thus easy to implement in the industry; it is linked to the sound level and its components [5], and can detect some faults before their effect is conclusive on current spectrum analysis, such as incipient bearing defects [6] and broken bars in rotors with a low interbar impedance [7].

Traditionally, vibration-based diagnosis has relied upon the detection of characteristic frequency components in the Fourier spectrum. This classical approach, however, may imply some drawbacks, just as it happens with currents. Among them, possible interference of frequency components caused by other failures or even non-fault-related phenomena, as well as inherent constraints of the Fourier analysis (spectral leakage, smearing or the spectrogram, picket fence effect, etc.) [8].

Thus, recently new methods based on the analysis of transient quantities, mainly stator currents, have been proposed. These approaches are based on the identification of characteristic signatures or patterns caused by the transient time-frequency evolutions of fault-related harmonics [8][10]. To this end, different time-frequency decomposition (TFD) tools have been proposed: Undecimated Discrete Wavelet Transform (UDWT) [11], Discrete Wavelet Transform (DWT) [8]-[9], [12]-[14], Continuous Wavelet Transform (CWT) [10], [15]-[16], Hilbert Transform (HT) [17], Hilbert-Huang Transform (HHT) [18]-[19], WignerVille (WVD) and Choi-Williams Distributions (CWD) [20][22] among others. These techniques have been proven valid in the case of analysis of transient currents. However, their application to other quantities is still pending, though a similar idea might be extrapolated in those cases.

Thus, the main contribution of this work is to demonstrate the viability of tracking characteristic fault-related components in the time-frequency maps resulting from the analysis of vibration signals captured during a transient. The resulting characteristic time-frequency patterns are employed to diagnose broken rotor bars in induction machines, a fact that opens a path for a future extension of the methodology to other faults. The Zhao-Atlas-Marks distribution (ZAM) is proposed as TFD tool. The reason is that it shows an adequate reduction of interferences called cross-terms between parallel evolving harmonics. In this paper, novel considerations related to the relative influence of interbar currents on the vibration time-frequency patterns are also discussed and supported by experimental tests.

For these purposes, the paper is organized as follows: Section II succinctly introduces the mathematical basis for the fault related components generation. Section III briefly explains the foundations of the ZAM. Section IV shows the test bed and the modified rotors used for the experimental validation. In Section V, the experimental results are shown, and Section VI yields the conclusions reached.

\section{Calculation of Fault Harmonics}

The rotating field approach, which represents the spatial distribution of the magnetic field in an induction motor as a series of rotating spatial harmonics is of widespread use for the calculation of vibration components [2,23]. The method establishes that the permeance value at the air-gap position $\theta$ in an instant $t, \Lambda(\theta, t)$, can be expressed as:

$$
\begin{aligned}
\Lambda(\theta, t)=\sum_{n_{1}=0}^{\infty} \sum_{n_{2}=0}^{\infty} \Lambda_{n_{1}, n_{2}} \\
\cdot \cos \left\{\left(n_{1} S \pm n_{2} R\right) \theta-n_{2} R \omega_{r} t\right\}
\end{aligned}
$$

where $S$ and $R$ are the number of slots in the stator and the rotor, respectively, $\omega_{r}$ is the rotational speed, $n_{1}, n_{2}$ are integers defining the multiples of the stator and rotor harmonics and $\Lambda_{n_{1}, n_{2}}$ is the peak specific permeance for the harmonic of order $n_{1}, n_{2}$. This expression takes only into account the effect of slotting (not considering saturation or eccentricity).

When a rotor bar exists, its effect on the m.m.f. rotor waves (3) can be decomposed in two components rotating in opposite directions. The negative sequence component causes a modulation at a frequency equal to twice the slip:

$$
\begin{aligned}
& \mathrm{F}_{\text {est }}(\theta, t)=\sum_{n_{3}=1}^{\infty} \sum_{n_{4}=-\infty}^{\infty} \mathrm{F}_{n_{3}, n_{4}} \cdot \cos \left(n_{3} p \theta-n_{4} \omega_{f} t\right) \\
& \mathrm{F}_{\text {rot }}(\theta, t)=\sum_{n_{5}=1}^{\infty} \sum_{n}^{\infty} \sum_{=-\infty}^{\infty} F_{n_{7}, n_{6}} \cdot \cos \left\{n_{5} p \theta\right. \\
& \left.-\left(n_{6} s \omega_{f}+n_{5} p \omega_{r}+n_{7} 2 s \omega_{f}\right) t\right\}
\end{aligned}
$$

where $p$ is the number of pole pairs, $s$ is the slip, $\omega_{f}$ is the supply frequency in $\mathrm{rad} / \mathrm{s}, n_{3}-n_{7}$ are integers denoting the different harmonic order and $\mathrm{F}_{n_{3}, n_{4}}$ is the peak magnetomotive force for the harmonic of order $n_{3}, n_{4}$.

Adding the m.m.f. waves of the stator (2) and the rotor (3) and multiplying the result by the permeance (1), an expression of the air gap flux density is obtained. This flux density varies both in space $\theta$ and time $t$. The contribution to the time harmonics' frequency is obtained evaluating the intermodulation of the time dependent components in (1)-(3), which yields:

$$
f_{s h 1}=\left\{\left(n_{2} R\right) \frac{1-s}{p} \pm n_{4}\right\} f
$$

for the stator and: 


$$
f_{s h 2}=\left\{\left(n_{2} R \pm n_{5} p\right) \frac{1-s}{p} \pm n_{6} s \pm n_{7} 2 s\right\} f
$$

for the rotor, being $f$ the supply frequency. These harmonics can induce currents in the stator windings. In addition, the flux density given by (4) causes radial force waves expressed per unit area, $\sigma(t)$, as:

$$
\sigma(t)=\frac{B^{2}(t)}{2 \mu_{0}}
$$

where $\mu_{0}$ is the permeability of free space. Therefore, these forces will also have a harmonic content which frequency is [2]:

$$
f_{s h 3}=\left\{\left(n_{2}^{\prime} R\right) \frac{1-s}{p} \pm n_{7}^{\prime} 2 s \pm n_{5}^{\prime}\right\} f
$$

being $n_{2}^{\prime}, n_{5}^{\prime}$ and $n_{7}^{\prime}$ integers indicating the harmonic order; that is, a rotor asymmetry causes a modulation of the rotor slot harmonics, the most prominent of which, for $n_{2}^{\prime}=1$, $n_{7}^{\prime}=0$ and $n_{5}^{\prime}$ low in (7), are known as principal slot harmonics (PSH). The effect of this modulation in the steady state current spectrum has already been studied in [24].

During a direct line startup transient of a faulty motor, as the slip $s$ varies, the frequencies of the components given by (7) will also evolve in a very characteristic way. At the connection instant, $(s=1)$ and for $n_{7}^{\prime}=1$, their frequency will differ $100 \mathrm{~Hz}$ from the PSH. As the rotor speed increases, these rotor bar fault components will converge towards this PSH to become its sidebands at $3 \mathrm{~Hz}$ during stationary operation $(s=0.03)$. Fig. 1 shows the theoretical evolution of $\mathrm{PSH}+2$, obtained for $n_{5}^{\prime}=+2\left(n_{7}^{\prime}=0\right)$ in $(6)$, and its sidebands for $n_{7}^{\prime}=1$ in the same equation, during such transient of an induction motor whose characteristics are presented in the Appendix. In general, during a direct startup several of these PSH can be detected.

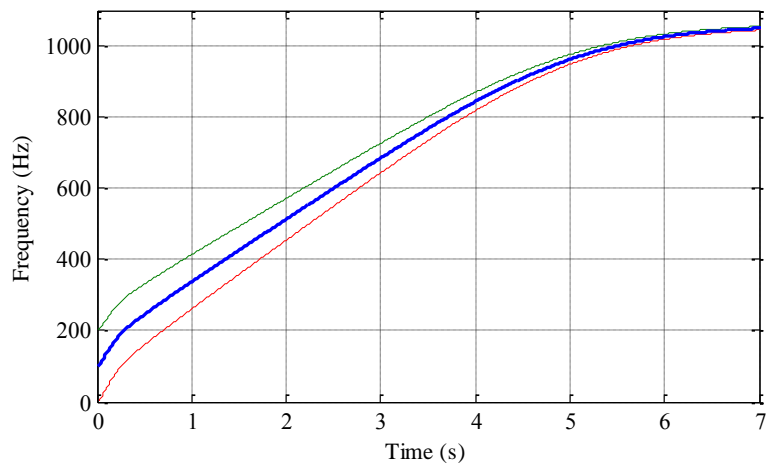

Fig. 1. Theoretical evolution of $\mathrm{PSH}+2$ and its converging sidebands during a direct startup.
In addition, throughout such a direct startup, the currents in the induction motor can be multiplied six times from the usual levels for stationary full load operation, and the frequency swept of the components may cross mechanical resonant regions [4], enhancing the asymmetry effects and facilitating detection.

Therefore, tracking of the transient evolutions of these components, by using proper time-frequency decomposition tools, such as the ZAM, can provide a valuable source of information for the diagnosis of the failure.

\section{The ZhaO-ATlas-Marks Distribution}

The Zhao-Atlas-Marks distribution (ZAM) is a type of Cohen class distribution which yields a time-frequency energy density whilst reducing the presence of interferences called cross terms. It has been derived from the Wigner-Ville distribution (WVD) that , for a given signal $x(t)$ is defined by (7), where $x^{*}$ denotes the conjugate of $x$. Hence, the Wigner integral is the Fourier transform, with respect to the delay variable $\tau$, of $x(t+\tau / 2) x *(t-\tau / 2)$, the instantaneous correlation. It has Hermitian symmetry in $\tau$ remaining always real [25].

$W V D_{X}(t, \omega)=\frac{1}{2 \pi} \int_{-\infty}^{+\infty} x\left(t+\frac{\tau}{2}\right) \cdot x^{*}\left(t-\frac{\tau}{2}\right) e^{-j \tau \omega} d \tau$

Among the advantages of the WVD is that it fulfills the marginal conditions [24], thus total signal energy can be computed in time or in frequency using the Plancherel expression (9), where $\|x(t)\|^{2}$ and $\|X(\omega)\|^{2}$ can be interpreted as energy densities in time and frequency, respectively.

$$
\|x\|^{2}=\int_{-\infty}^{+\infty}|x(t)|^{2} d t=\frac{1}{2 \pi} \int_{-\infty}^{+\infty}|X(\omega)|^{2} d \omega
$$

However, the application of the WVD is affected when applied to the analysis of multicomponent signals, due to the appearance of artifacts between harmonics (cross terms). The way of dealing with this drawback usually implies, firstly, to compute the time-frequency distribution of the analytic signal of the analyzed waveform; since the Fourier transform of an analytic signal has no negative components, this procedure removes their interaction with their symmetric positive ones. Moreover, other filtering techniques are applied; one of them consists in carry out these procedures on the ambiguity plane using a tailored function called kernel, which yields different time-frequency distributions with changing properties, such as the Choi-Williams distribution and the Zhao-Atlas-Marks distribution, whose kernel is:

$$
\phi_{Z A M}(\vartheta, \tau)=g(\tau)|\tau| \frac{\sin (a \vartheta \tau)}{a \vartheta \tau}
$$


where $g(\tau)$ is a given function and $a$ a given parameter. This yields the expression for the computation of the ZAM [25]:

$$
\begin{aligned}
& Z_{X}(t, \omega)=\frac{1}{4 \pi a} \int_{-\infty}^{+\infty} g(\tau) e^{-j \tau \omega} . \\
& \cdot \int_{t-a|\tau|}^{t+a|\tau|} x\left(t+\frac{\tau}{2}\right) \cdot x^{*}\left(t-\frac{\tau}{2}\right) d t d \tau
\end{aligned}
$$

However, all these modifications come at the expense of computational time and resolution limitations or loss of desirable properties. For the particular case of the ZAM, the fulfilling of the marginals (9) depends on the selection of $g(\tau)$ and $a$ [25]. Nevertheless, the distribution can yield a good indication of the harmonic structure of the signal.

For its computation and the representation of the results, the TFTB Toolbox developed by CNRS (France) and Rice University (USA) for MATLAB has been used in this work [26].

\section{EXPERIMENTAL SETUP}

The proposed method has been validated experimentally with a PC-based offline diagnosis system by testing two commercial motors with the same characteristics (see Appendix), one healthy and another one featuring a broken bar. The defect was produced drilling a rotor bar in its junction with the short circuit ring, firstly on one end, and then also at the opposite side of the bar, in order to reduce interbar currents (see Fig. 3). The induction motor is mechanically coupled to a DC machine (Fig. 2) and tested at full load. The total inertia of the group is estimated in 0.11 $\mathrm{kg} \cdot \mathrm{m}^{2}$.

The test equipment consists of two $100 \mathrm{mV} / \mathrm{g}$ shear accelerometers mounted on magnetic bases and connected to a NI USB-9234 module. Acceleration in the radial and axial directions during the direct line startup transient are captured at a rate of $10 \mathrm{kHz}$ with a resolution of 24 bits.

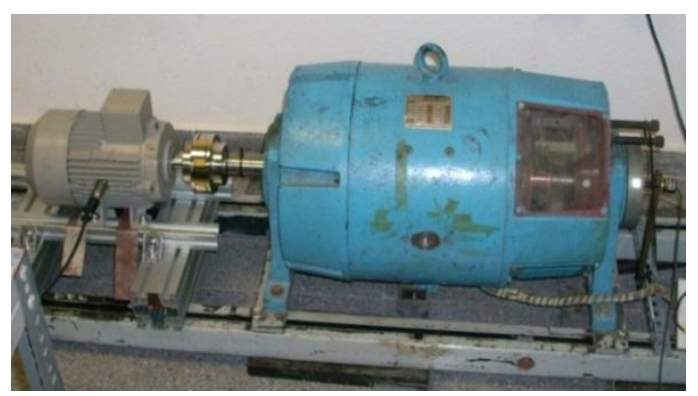

Fig. 2. Experimental test stand

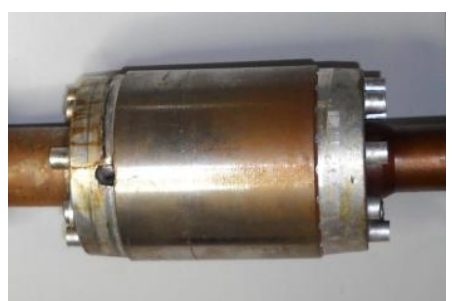

(a)

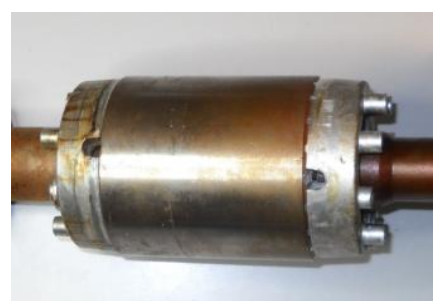

(b)
Fig. 3. Rotor featuring a broken rotor bar: (a) at one end, (b) at both ends (no interbar currents can flow).

\section{RESULTS AND DISCUSSION}

In this section, firstly qualitative and quantitative results are presented, followed by other analysis that complement the information provided.

\section{A. Time-Frequency Analysis}

The ZAM transient-based technique was applied to analyze vibration signals obtained by the accelerometers. These vibration signals were captured from the startup transients of the two machines under the three different conditions: healthy, one broken bar drilled at one end and one broken bar drilled at both ends; and were down sampled to $2.5 \mathrm{kHz}$ before applying the analysis procedure. Fig. 4 shows one of these signals in which it can be observed that the peak vibration acceleration during the startup (0-7 seconds) is much greater than at stationary level (7-8 seconds), almost doubling it as the rotor crosses a resonant region between 4000 and 5200 milliseconds.

Fig. 5 presents the ZAM analysis for the healthy case. This figure shows Principal Slot Harmonics (PSH's), obtained for $n_{2}^{\prime}=1$ in (7), evolving towards their corresponding stationary-state frequencies. The highest amplitude corresponds to the $\mathrm{PSH}+2\left(n_{5}^{\prime}=2\right)$, which from $100 \mathrm{~Hz}$ at startup reaches $1067 \mathrm{~Hz}$ at the end of the transient (a1). The initial evolution of the PSH-2 is also shown $\left(n_{5}^{\prime}=-2\right)$.

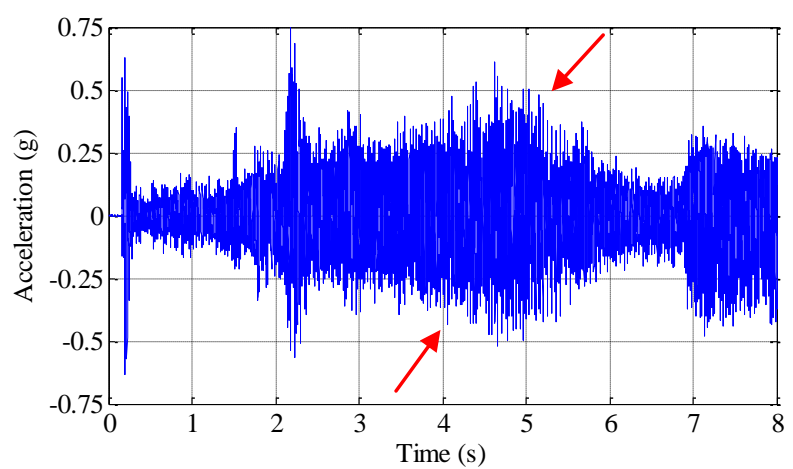

Fig. 4. Waveform of the captured axial vibration acceleration for an induction motor having one broken bar. The red arrows indicate the resonant region between 4 and $5.2 \mathrm{sec}$. 
ZAM-Healt., radial, $\mathrm{Lg}=200, \mathrm{Lh}=150, \mathrm{Nf}=600$, log. scale, Thr. $=0.5 \%$



Fig. 5. Zhao-Atlas-Marks distribution of the startup vibration transient of a healthy induction motor, high frequencies.

On the other hand, Fig. 6, shows the ZAM vibration analysis for the case of a machine having one broken bar severed at one end. In this case, converging sidebands (b2, b3) around the PSH+2 (b1) appear. It can be observed that at approximately half the startup transient interval $(t=3.5 \mathrm{~s})$, they differ $50 \mathrm{~Hz}$ from the PSH they are approaching. Therefore, it can be concluded that these traces are produced by $2 s f$ sidebands, thus this effect can be attributed to the failure.

ZAM- BB 1 end, radial, $\mathrm{Lg}=200, \mathrm{Lh}=150, \mathrm{Nf}=600$, log. scale, Thr. $=0.5 \%$

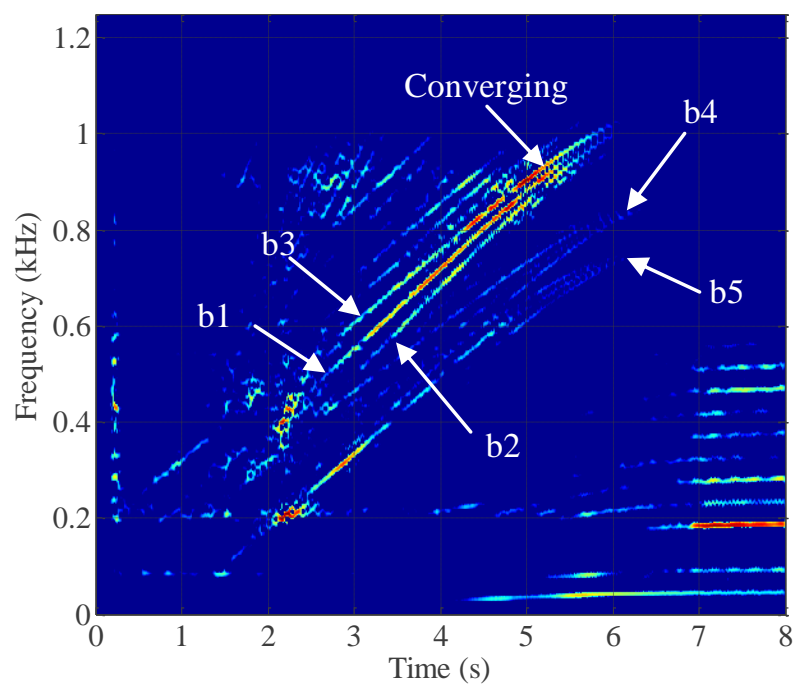

Fig. 6. Zhao-Atlas-Marks distribution of the startup vibration transient of an induction motor with one broken bar, high frequencies. Sidebands converge around three PSH.

In addition, the sidebands are also appreciated in the evolution of the PSH-3 (b4) and the PSH-4 (b5), for $n_{5}^{\prime}=-3$ and -4 , respectively.
Nevertheless, Fig. 7 shows how the aforementioned sidebands vanish in the ZAM time-frequency plot if the bar is severed at both ends. The PSH-3 $\left(n_{2}^{\prime}=1, n_{5}^{\prime}=-3\right)$ also strongly appears (c1) and in general the distribution is noisier.

\section{ZAM- BB 2 ends, radial, $\mathrm{Lg}=200, \mathrm{Lh}=150, \mathrm{Nf}=600, \log$. scale, $\mathrm{Thr} .=0.5 \%$}

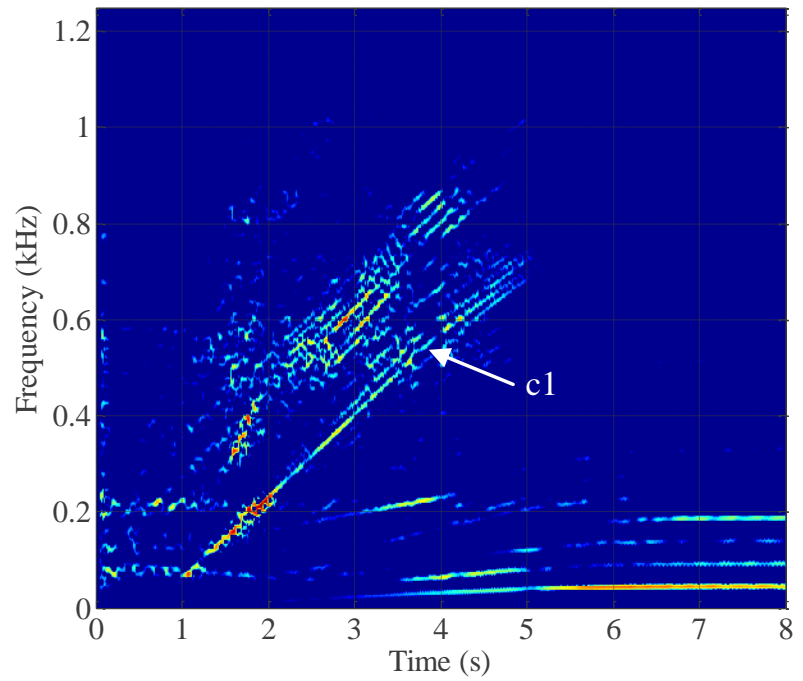

Fig. 7. Zhao-Atlas-Marks distribution of the startup vibration transient of an induction motor with one broken bar severed at both ends.

\section{B. Quantification parameter}

Although time-frequency distributions offer wide possibilities for quantifying the energy present in determined harmonics of the signal, in this particular case, a straightforward quantification parameter can be derived from these results, comparing the energy present at high frequency against the total energy of the waveform for the same time limits.

For this purpose, following the indications obtained by the time-frequency analysis, a time-frequency box is defined having frequency limits of $700 \mathrm{~Hz}$ and $1.1 \mathrm{kHz}$ and time limits from the instant the $\mathrm{PSH}+2$ harmonic reaches the lower frequency limit up to 2.5 seconds later (Fig. 8). The energy at those high frequencies and time range is obtained by means of band pass filtering, using a FIR filter and normalizing it with the total energy of the signal. The results of this ratio $\gamma_{H F}$ for each case, clearly indicating the higher high frequency harmonic content in the case of a bar breakage at one end for that time range, are shown in Table I:

TABLE I

\begin{tabular}{cc}
\multicolumn{2}{c}{ QUANTIFICATION RESULTS } \\
\hline State & $\gamma_{\mathbf{H F}}(\%)$ \\
\hline Healthy & 22.3 \\
Broken bar, 1 end & 85.6 \\
Broken bar, 2 ends & 30.3 \\
\hline
\end{tabular}


ZAM- BB 1 end, radial, Lg=200, Lh=150, Nf=600, log. scale, Thr. $=0.5 \%$

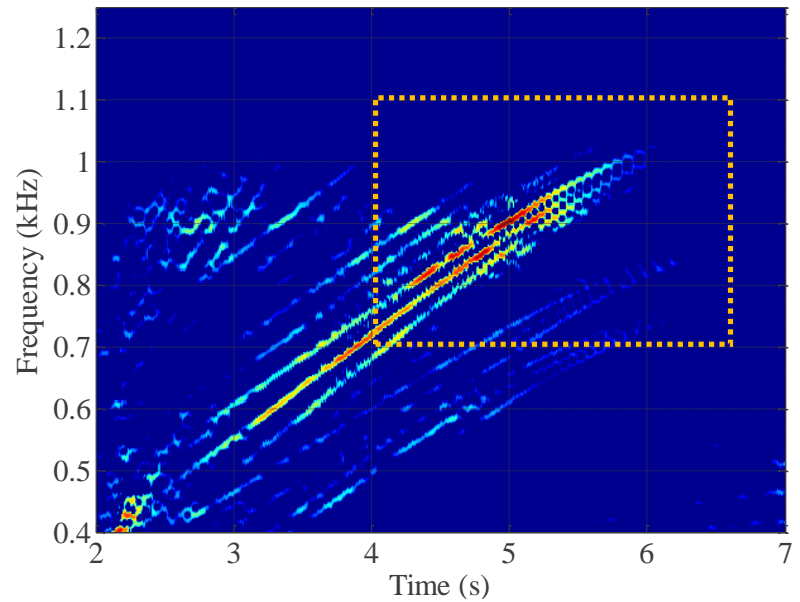

Fig. 8. Time-frequency box defined in order to establish a quantification parameter for the case of the bar broken at one of its ends.

\section{Study of interbar currents}

The study of the stationary vibration spectrum of all these cases reveals the reduction of interbar currents when the bar is severed at both ends (Fig. 9). According to [7], the vibration harmonic in the axial direction having a frequency of $(6-6 s) f$ is a good indicator of such currents, which appear even in a healthy machine due to skewing. The harmonic around $291 \mathrm{~Hz}$ suffers a reduction of almost one order of magnitude when the bar is broken on both junctions to the end rings (d1), compared to one end breakage $(\mathrm{d} 2)$, reaching half the value for the healthy state (d3). For comparison, the $300 \mathrm{~Hz}$ component, a $2 f$ harmonic, differs much less (d4).

\section{Currents in bars}

Finally, an analysis by the Finite Element Method using FLUX $^{\mathrm{TM}}$ illustrates the tough conditions that happen during a direct line startup with high inertia, which made possible this novel diagnosis method. Fig. 10 shows the current waveforms during the transient in a bar next to the broken one (Bar 19) and in one opposite to that one (Bar 10) -which is similar to that existing in all the bars of a healthy machinefor the motor used in the tests.

The comparison between both cases shows that the average RMS value of the current during the transient differs between bars $35 \%$, from 735.8 A to 994.2 A. During the stationary operation, however, this difference is reduced to $18.5 \%$.

As a summary, transient-based vibration analysis is proven to be a reliable tool to diagnose rotor bar breakages, taking advantage of the severe conditions the motor suffers during this kind of operation. Moreover, its potential extension to other failures such as mixed eccentricities, bearing faults or other faults introducing slip-dependent frequencies becomes, at least, promising.

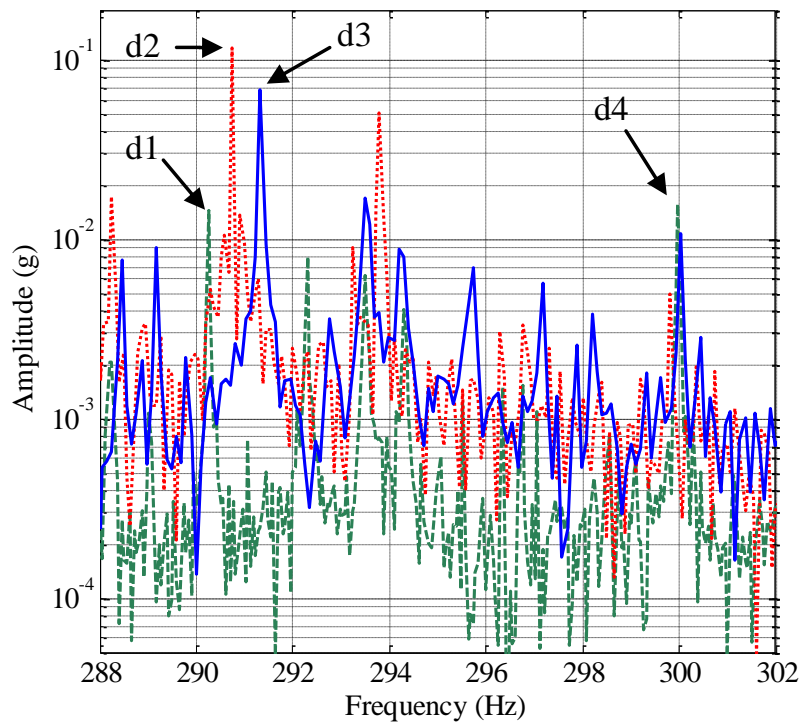

Fig. 9. Spectrum of the axial vibration for the healthy motor (blue, solid), the motor having a broken bar (red, dotted) and the motor having a broken bar cut at both of its ends (green, dashed).
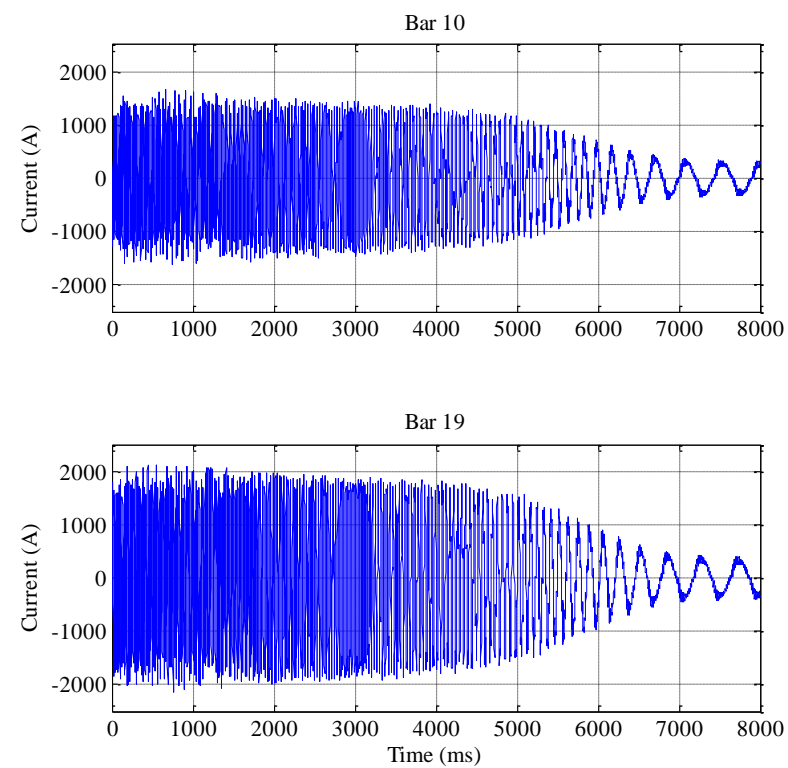

Fig. 10. Currents in bars obtained by the Finite Element Method for the tested machine during the startup: above (Bar 10), usual current in a bar; below (Bar 19), current in a bar next to the broken one.

An issue to be considered when applying the methodology is the startup length. A very short startup length may complicate the identification of the qualitative fault signatures rising in the time-frequency maps. Nonetheless, this is not a crucial restriction for the industrial application of this type of methodologies, since rotor bar breakages and 
other failures are much more likely in large motors, starting under high inertias. These large motors are usually the most expensive and difficult to repair. Typically, direct startups in those motors under the aforementioned conditions (large inertias of the group motor-load) can perfectly last several seconds.

\section{CONCLUSIONS}

This paper proposes and proves, for the first time, the validity of transient-based vibration analysis to diagnose electromechanical failures in induction machines.

Following an analogue methodology to the recently introduced transient-based current analysis approach, first, the work theoretically studies and characterizes the transient evolutions of the harmonics caused by broken bars, focusing on those evolving around the PSH's. Then, different vibration signals are captured by using an experimental test bed. Subsequent application of the proposed TFD tool, the ZhaoAtlas-Marks distribution, reveals that, during the startup transient of a motor featuring a broken bar, axial vibration PSH components show converging sidebands which reach $\pm 2 \mathrm{sf} \mathrm{Hz}$ at steady state. These evolutions constitute reliable indicators of the failure.

In the work, influence of interbar currents are also studied, revealing an attenuation of the time-frequency patterns if the bar is severed at both ends and interbar currents are greatly reduced, as it can be proved by the analysis of the vibration spectrum during stationary operation.

Transient-based vibration analysis becomes a tool with great future potentiality, especially in critical applications in which vibration measurements are also available as well as in applications in which current-based diagnostic is uncertain.

\section{APPENDIX}

Motor characteristics: Star connected, rated voltage $\left(\mathrm{U}_{\mathrm{n}}\right)$ : $400 \mathrm{~V}$, rated power $\left(\mathrm{P}_{\mathrm{n}}\right): 1.5 \mathrm{~kW}, 1$ pole pairs, stator rated current $\left(\mathrm{I}_{1 \mathrm{n}}\right): 3.25$ A rated speed $\left(\mathrm{n}_{\mathrm{n}}\right): 2860 \mathrm{rpm}$, number of rotor bars: 20 .

\section{REFERENCES}

[1] W. R. Finley, M. M. Hodowanec, W. G. Holter, "Diagnosing Motor Vibration Problems", Pulp and Paper Industry Technical Conference, 2000. Conference Record of 2000 Annual, 2000, pp. 165 - 180

[2] J. R. Cameron, W. T. Thomson, A. B. Dow, "Vibration and current monitoring for detecting airgap eccentricity in large induction motors", IEE Proceedings, Vol. 133, Pt. B, No. 3, May 1986, pp. 155-163

[3] P. J. Rodriguez, A. Belahcen, A. Arkkio, "Signatures of electrical faults in the force distribution and vibration pattern of induction motors", IEE Proc. -Electr. Appl., Vol. 153, No. 4, July 2006, pp. 523529

[4] A. Bellini, C. Concari, G. Franchescini, C. Tassoni, A. Toscani, "Vibrations, currents and stray flux signals to asses induction motors rotor conditions." IEEE Industrial Electronics, IECON 2006 - 32nd Annual Conference on, 2006 , pp. 4963 - 4968

[5] V. Lanfranchi, G. Friedrich, J. Le Besnerais, M. Hecquet, "Spread spectrum strategies study for induction motor vibratory and acoustic behavior", IEEE Industrial Electronics, IECON 2006 - 32nd Annual Conference on, 2006 , pp. 1423 - 1428

[6] F. Immovilli, A. Bellini, R. Rubini, C. Tassoni, "Diagnosis of Bearing Faults in Induction Machines by Vibration or Current Signals: A Critical Comparison", IEEE Trans. Ind. Appl., Vol. 46, No. 4 July/August 2010, pp. 1350-1359

[7] G. H. Müller, F. Landy, "A Novel Method to Detect Broken Rotor Bars in Squirrel Cage Induction Motors When Interbar Currents are Present", IEEE Trans. Energy Conv., Vol, 18, No. 1, March 2003, pp. $71-79$.

[8] M. Riera-Guasp, J. A. Antonino-Daviu, M. Pineda-Sanchez, R. PuchePanadero, and J. Perez-Cruz, "A General Approach for the Transient Detection of Slip-Dependent Fault Components Based on the Discrete Wavelet Transform," IEEE Trans. Ind. Electron., vol. 55, pp. 41674180, 2008.

[9] S.H. Kia, H. Henao and G.A. Capolino, "Diagnosis of Broken-Bar Fault in Induction Machines Using Discrete Wavelet Transform Without Slip Estimation," IEEE Trans. Ind. Appl., Vol. 45, No. 4, July/August 2009, pp. 1395-1404.

[10] F. Briz, M.W. Degnert, P. Garcia, D. Bragado, "Broken rotor bar detection in line-fed induction machines using complex wavelet analysis of startup transients," IEEE Trans. Ind. Appl., Vol. 44, No. 3, May-June 2008, pp. 760-768.

[11] W. G. Zanardelli, E. G. Strangas, and S. Aviyente, "Identification of Intermittent Electrical and Mechanical Faults in Permanent-Magnet AC Drives Based on Time-Frequency Analysis," IEEE Trans. Ind. Appl., vol. 43, pp. 971-980, 2007.

[12] J. A. Antonino-Daviu, M. Riera-Guasp, J. R. Folch, and M. Pilar Molina Palomares, "Validation of a new method for the diagnosis of rotor bar failures via wavelet transform in industrial induction machines," IEEE Trans. Ind. Appl., vol. 42, pp. 990-996, 2006

[13] A.Ordaz-Moreno, R.Romero-Troncoso, J.A.Vite-frías, J.RivieraGillen, A.García-Pérez, "Automatic online diagnostic algorithm for broken-bar detection on induction motors based on Discrete Wavelet Transform for FPGA implementation", IEEE Trans. Ind. Electron., vol.55, no.5, pp.2193-2200, May. 2008

[14] H. Douglas, P. Pillay, and A. Ziarani , "Broken rotor bar detection in induction machines with transient operating speeds," IEEE Trans. Energy Conv., vol. 20, no. 1, pp. 135-141, March 2005.

[15] S. Rajagopalan, J.M. Aller, J.A. Restrepo, T.G. Habetler and R.G. Harley, "Analytic-Wavelet-Ridge-Based Detection of Dynamic Eccentricity in Brushless Direct Current (BLDC) Motors Functioning Under Dynamic Operating Conditions", IEEE Trans. Ind. Electron., vol. 54, no. 3, pp. 1410-1419, June 2007.

[16] J. Cusido, L. Romeral, J.A. Ortega, J.A. Rosero, A. Garcia Espinosa, "Fault Detection in Induction Machines Using Power Spectral Density in Wavelet Decomposition," IEEE Trans. Ind. Electron., vol. 55, no. 2, pp. 633-643, Feb. 2008

[17] R. Puche-Panadero, J. Pons-Llinares, J. Roger-Folch and M. PinedaSánchez, "Diagnosis of eccentricity based on the Hilbert Transform of the Startup Current", proc. of SDEMPED 2009, Cargese (France), September 2009.

[18] J.A. Antonino-Daviu, M. Riera-Guasp, M. Pineda-Sánchez, R.B. Pérez, "A Critical Comparison Between DWT and Hilbert-Huang-Based Methods for the Diagnosis of Rotor Bar Failures in Induction Machines", IEEE Trans. Ind. Appl., vol. 45, no. 5, pp: $1794-1803$, Sept.-Oct. 2009

[19] Z.K. Peng, P.W. Tse, F.L. Chu, "A Comparison Study of Improved Hilbert-Huang Transform and Wavelet Transform: Application to Fault Diagnosis for Rolling Bearing", Mechanical Systems and Signal Processing, Elsevier, Vol. 19, 2005, pp. 974-988.

[20] M. Blodt, D. Bonacci, J. Regnier, M. Chabert, and J. Faucher, "OnLine Monitoring of Mechanical Faults in Variable-Speed Induction Motor Drives Using the Wigner Distribution," IEEE Trans. Ind. Electron., vol. 55, pp. 522-533, 2008.

[21] S. Rajagopalan, J.M. Aller, J.A. Restrepo, T.G. Habetler, R.G. Harley, "Detection of Rotor Faults in Brushless DC Motors Operating Under Nonstationary Conditions," IEEE Trans. Ind. Appl., vol.42, no.6, pp.1464-1477, Nov-Dec. 2006. 
[22] V. Climente-Alarcón, J.A. Antonino-Daviu M.Riera-Guasp, R. Puche, L. Escobar-Moreira, P. Jover-Rodriguez, A. Arkkio, "Diagnosis of stator short-circuits through Wigner-Ville transient-based analysis", in Proc. of 35th Annual Conference of the IEEE Industrial Electronics Society, IECON 2009, Porto (Portugal), November 2009.

[23] Burakov, A., Arkkio, A.,Comparison of the Unbalanced Magnetic Pull Mitigation by the Parallel Paths in the Stator and Rotor Windings, IEEE Trans. Magn., Vol. 43, no. 12, 2007, pp. 4083 - 4088

[24] A. Khezzar, M. Y. Kaikaa, M. El Kamel Oumaamar, M. Boucherma, H. Razik, "On the Use of Slot Harmonics as a Potential Indicator of Rotor Bar Breakage in the Induction Machine", IEEE Trans. Ind. Electron., vol.56, no.11, pp. 4592-4605, Nov. 2009

[25] L. Cohen, Time-Frequency Analysis. A.V. Oppenheim, Ed. Prentice Hall Signal Processing Series, New Jersey, 1995.

[26] F. Auger, P. Flandirn, P. Gonçalvès, O. Lemoine, "Time Frequency Toolbox to Use with Matlab" CNRS (France) \& Rice University (USA) 1995-1996

Vicente Climente-Alarcon received his M.Sc. degrees in Chemical and Industrial Engineering in 2000 and 2011, and his Ph.D. degree in Electrical Engineering in 2012, all from the Universidad Politecnica de Valencia (Spain). Currently he is an Assistant Professor in the School of Industrial Engineering of the mentioned university, carrying out research tasks in the area of condition monitoring of electrical machines, and works externally as a consultant in automation and management of power systems.
Jose A. Antonino-Daviu received the M.Sc. degree in Electrical Engineering from the Universidad Politecnica de Valencia in 2000 and the Ph.D. degree in Electrical Engineering in 2006. He worked in the private sector, being involved in several international projects. Currently, he is Associate Professor in the School of Industrial Engineering of the mentioned university, where he develops his docent and research work. His primary research interests are condition monitoring of electric machines, wavelet theory and its application to fault diagnosis and designand optimization of electrical installations and systems.

Francisco Vedreño-Santos received the M.Sc degree in electrical engineering from Universidad Politecnica de Valencia, Spain, in 2008, where he is currently working toward the Ph.D. degree in electrical engineering in the Departamento de Ingeneria Eléctrica. His research interests include electric-machine diagnostics, condition monitoring of electric machines and windmills.

Ruben Puche-Panadero obtained his MSc. in Automatic and Electronic Engineering in 2003 from the Universidad Politécnica de Valencia. From 2003 to 2006 he worked in a Innovate European Project of Automation as Developer of Plc's Program, Scada, Panels, etc. Since 2006 he joined the Universidad Politecnica de Valencia and he is currently Professor of Machines Control. His research interests focus in induction motor diagnostics and maintenance, numerical modeling and automation of industrial installations. 